\title{
The Retrieve and Data Fusion of the Sea Surface Temperature with FengYun Geostationary Satellite Data
}

\author{
Wang Wei", Wu Danzhu, Qu Pin, Li Yi, Liu Lili, Wu Bingui \\ Tianjin Institute of Meteorological Science, Tianjin, China \\ Email address: \\ wwei356@163.com (Wang Wei), Danzhu_wu@yahoo.com (Wu Danzhu), q12p19@126.com (Qu Pin), Linyi14@163.com (Li Yi), \\ lililiuwuwu@126.com (Liu Lili),tjwbg@yahoo.com (Wu Bingui) \\ ${ }^{*}$ Corresponding author
}

\section{To cite this article:}

Wang Wei, Wu Danzhu, Qu Pin, Li Yi, Liu Lili, WuBingui. The Retrieve and Data Fusion of the Sea Surface Temperature with FengYun Geostationary Satellite Data. Journal of Water Resources and Ocean Science. Vol. 5, No. 4, 2016, pp. 53-63. doi: $10.11648 /$ j.wros.20160504.12

Received: July 12, 2016; Accepted: July 22, 2016; Published: August 6, 2016

\begin{abstract}
The numerical weather prediction (NWP) model about marine meteorological disasters requires sea surface temperature (SST) data which represents the parameters of marine dynamic process. However, the SST data of high spatial-temporal resolution are scarce in Huang Bohai sea in China. In order to acquire the high resolution SST data, the authors try to retrieve the high resolution SST data in Huang Bohai sea with FY2G-based satellite data. Moreover, the data differences of the satellite retrieval data with both buoys observation SST and NCEP optimal interpolation SST are compared, respectively, in terms of the statistical analysis method. Meanwhile the statistical equations are determined about the satellite retrieval SST with observed SST and of optimal interpolation SST. The equations are referred as a standard of data quality control equations when the differences of the revised values of the statistical equations and satellite inversion are calculated. While the data fusion is done, authors retain the data that the differences of the satellite retrieval SST and the statistical equation are less than $3.0^{\circ} \mathrm{C}$. Above method could make that the satellite SST space characteristic information is merged into weekly average optimal interpolation SST data, and it improves SST spatial-temporal resolution in Huang Bohai sea. The work lays a foundation for numerical models using the high resolution SST in Huang Bohai area.
\end{abstract}

Keywords: FY Geostationary Satellite, SST, Inversion Data, Data Fusion

\section{Introduction}

SST plays a crucial role in the air-sea energy exchange, and is an important factor of affecting weather and climate system (Yu et al. 2011; Fisher et al. 2004; BOOTH et al. 2011). Some research results show that the energy exchange and marine advection on the air-sea interface together control the formation, maintain and attenuation of sea surface temperature anomalies. Another results show that SST changes have influence on the typhoon path (EMANUEL et al. 1986; RIEHL et al. 1950; WANG et al. 2012). Moreover, some typhoons moving path is the more sensitive to the change of SST. Under the influence of SST anomaly, synoptic-scale oscillation frequency significantly change and prone to unstable oscillation. The oscillation is stability when SST value is low. With the SST value increasing, the oscillation frequency becomes the lower and wave velocity also is the slower (Yu et al. 2006).

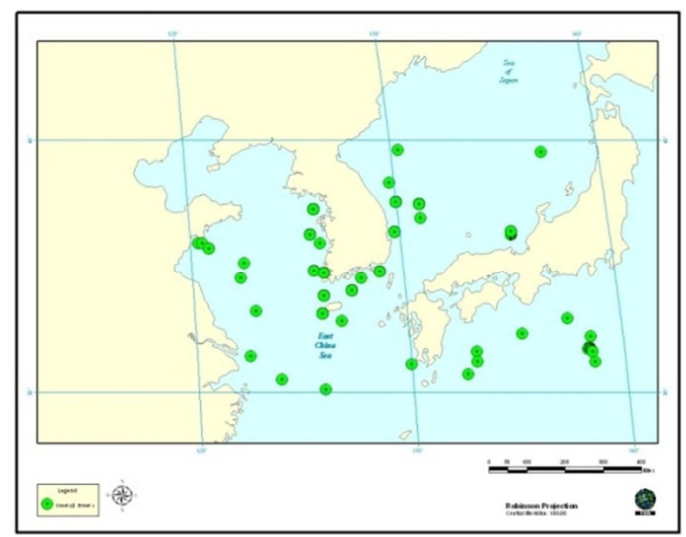

Fig. 1. The station distribution in CCIMISS database. 
In operational forecasting of sea disaster in North China, forecasters also found that sea surface temperature have a significant impact on the accuracy of marine numerical prediction model ( $\mathrm{Su}$ et al. 2001; WANG et al. 2007). However, Fig. 1 shows that the SST of the Bohai sea is still very scarce in the CIMISS database of China meteorological administration, as limited due to the funding and technical conditions. The SST data are unable to meet the needs of marine forecast operation.

Although the SST retrieved by satellite data can provide high resolution SST for numerical weather prediction models, the most of operational retrieval SST use global retrieval algorithms based on a global scale standard that its accuracy is often difficult to meet the application requirement of local sea area (Maul G, 1981; Wentz et al. 2000). In addition, its spatial resolution is too low to apply although the grid SST can cover the global ocean.

In order to improve the forecasting ability of the NWP model on the marine disasters, it is necessary to prepare to the high resolution grid SST of daily or half daily average data for models. Therefore, this paper tries to utilize the remote sensing data of the stationary satellite to retrieve SST on the Huang-Bohai area, and merge the retrieve SST into NCEP SST. The aim is to acquire the technology of the daily or half daily average SST with high resolution under the condition of ultra shallow sea.

\section{Data and Method}

\subsection{Data Source}

The $0.5^{\circ} \times 0.5^{\circ}$ weekly average grid SST is used in operational NWP models in Tianjin. Although the SST play an important role in daily weather forecasting, the defects of low temporal-spatial resolution are also appeared in the weather forecasting of mid- and small- scale around Huang Bohai. Therefore, the fine grid SST in Huang-Bohaisea is necessary to be obtained.

Thestationary satellite data of retrieving the SST come from FY2G-based hourly data which is received in Tianjin Meteorological Administrative. Data projection is Geographic Lat/Lon. The retrieval SST region locates at $\left(20^{\circ}\right.$ to $45^{\circ} \mathrm{N}$, $115^{\circ} \sim 140^{\circ} \mathrm{E}$ ), where contains the main sea area managed by the North Ocean Center of the China Meteorological Administrative.

The first guest field of fusion data come from the NCEP optimal interpolation data of $1^{\circ} \times 1^{\circ}$ weekly average global SST. The observed SST data is the hourly SST of the buoys or the ships from the CIMISS database of the China Meteorological Administrative.

The period of Stationary satellite data, the optimal interpolation data and buoy data is from September 2015 to February 2016.

\subsection{The Retrieval Method of Sea Surface Temperature Based on Geostationary Satellite Data}

The SST retrieval software of geostationary satellite data was developed by Nanjing university, which the retrieval algorithm use the NLSST algorithm shown as follow:

$$
\begin{aligned}
& N L S S T=A_{0} T B_{11}+A_{1}\left(T B_{11}-T B_{12}\right) S S T_{F G} \\
& +A_{2}\left(T B_{11}-T B_{12}\right)(\sec \theta-1)+\text { const }
\end{aligned}
$$

$\theta$ is satellite zenith angle, $\mathrm{SST}_{\mathrm{FG}}$ is the first guess SST. The NLSST is firstly calculated with the $11 \mu \mathrm{m}$ infrared brightness data in operational application, and then substitute NLSST calculation values for $\mathrm{SST}_{\mathrm{FG}}$. The equation coefficients of $\mathrm{A}_{0}$, $A_{1}, A_{2}$ and const are obtained through the retrieval SST matched buoy SST in terms of the 200 group data. This algorithm was verified in the East China Sea.

Table 1. The equation coefficient of sea surface temperature.

\begin{tabular}{llll}
\hline $\mathbf{A}_{\mathbf{0}}$ & $\mathbf{A}_{1}$ & $\mathbf{A}_{2}$ & CONST \\
\hline 1.02758 & 0.00591709 & 0.772780 & -5.49078 \\
\hline
\end{tabular}

\subsection{The Theory of Data Fusion}

In order to solve the problem that the high-resolution SST is insufficient in Huang-Bohai area, the authors retrieve the high spatial and temporal resolution SST of Huang-Bohai area, and merge into NCEP weekly average grid SST.

Data fusion method uses the poisson equation in which $\mathrm{S}$ is the anomaly of the retrieval SST and the symbol $\Phi$ is the anomaly of fusion data. The $\Phi$ is calculated as follow:

$$
\nabla^{2} \Phi=\rho
$$

The $\rho$ in the above equation is define as follow:

$$
\rho=\nabla^{2} S
$$

In the pratical application, the area of NCEP grid SST is greater than the retrieval SST region, and both the boundary values and cloud coverage are set to zero.

In order to reduce the fusion errors, the differences of the retrieval SST and the calculation results with formula (3) is applied to merge the data with poisson equation. Thereafter, the region differences treated by poisson equation are integrated into NCEP grid SST. This treatment can integrate the spatial characteristics of the satellite retrieval SST into NCEP grid data in order to ensure the rationality of the regional SST.

\section{The Analysis of SST Characteristics in the North China Sea}

In operational NWP model, the traditional idea is thought that the SST is no obvious diurnal variation, and models could use monthly or weekly SST. But the SST observed at A oil platform on bohai indicates that there are the diurnal variation of $1.5^{\circ} \mathrm{C} \sim 2.0^{\circ} \mathrm{C}$. According to the analysis of three-year monthly average data of 6 stations on the Bohai sea, the difference of $2^{\circ} \mathrm{C} \sim 3^{\circ} \mathrm{C}$ appears betweenthe different positions. The monthly SST shows that the lowest SST occurs 
in January about $0^{\circ} \mathrm{C}$ and the highest value in August about $25^{\circ} \mathrm{C}$.

The SST is high correlation with the air temperature on sea, and keeps the consistent change. Moreover, the SST is less than the air temperature between February to July, and greater than the air temperature between August to January.

The above analysis show that the SST of Huang-Bohai obviously appears the diurnal and spatial variation characteristics which the ranges is about $2^{\circ}-3^{\circ} \mathrm{C}$. This variation amplitude maybe have influence on the strength of coastal mid- and small-scale weather system.
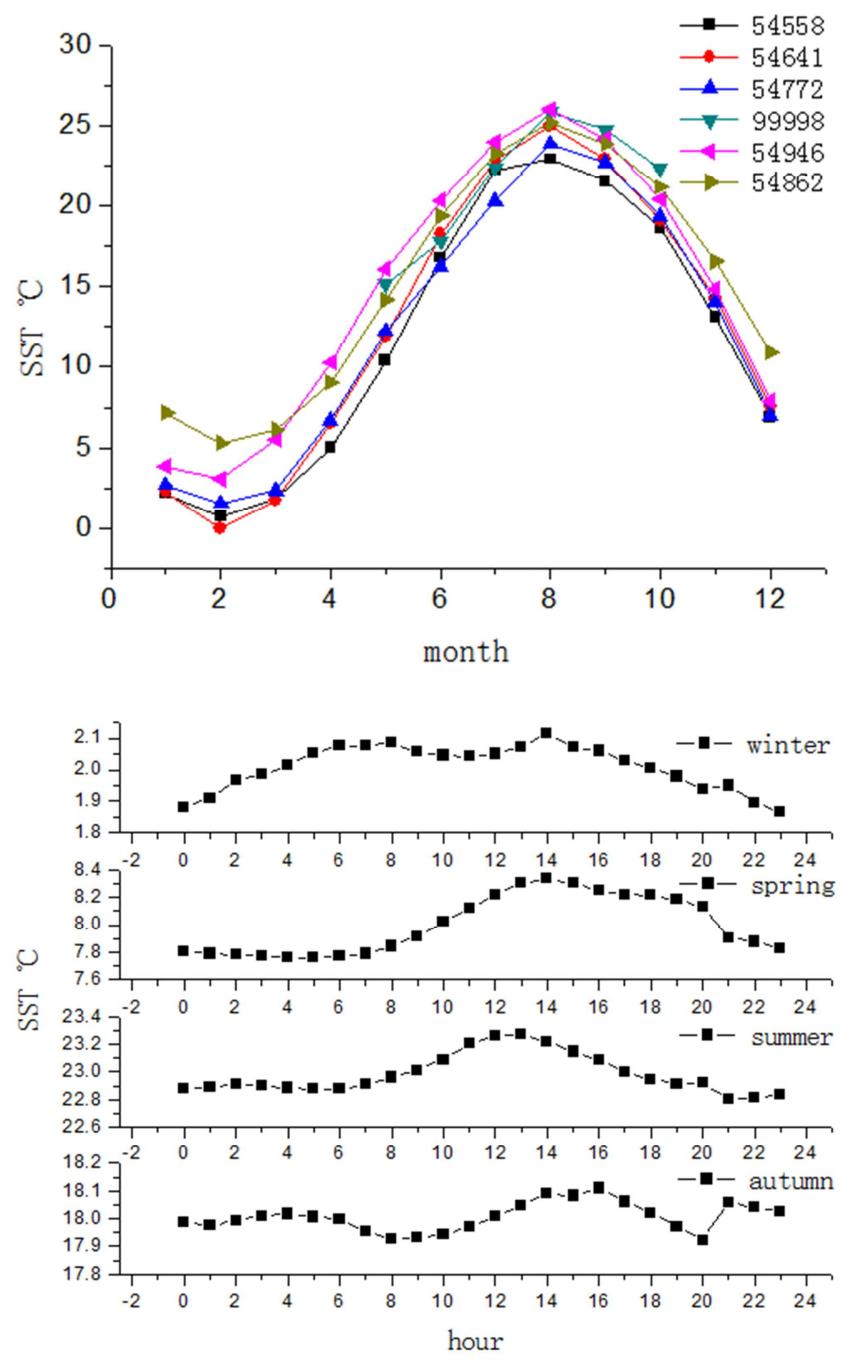

Fig. 2. The observation values of stations in Bohaisea (a) the monthly sst value of six station (b) the seasonal sst of A oil platform in Bohai sea.

\section{The Quality Control of the Retrieval Sea Surface Temperature with Geostationary Satellite Data}

\subsection{The Quality Control Problem of the Retrieval Sea Surface Temperature}

Because the SST observed by satellites is affected by the cloud, the SST retrieval accuracy greatly depends on the precision of cloud detection algorithm. When the SST data is retrieved with FY2G-based brightness in this paper, the area of cloud coverage is removed with the cloud mask technology. At present, there are three kinds of cloud mask technology. (1) the single channel threshold is the most common method of cloud masking for the optical channel information can directly reflect the characteristics of cloud optical thickness, so the method has the higher precision to detect cloud. (2) The difference method of 11 micron and 12 micron infrared brightness. When cloud coverage exists, the difference value is very small so that cirrus is removed well. (3) The difference of the 3.7 micron and 12 micron infrared brightness is suitable to mask the low clouds and fog. The 3.7 micron infrared brightness is the more sensitive to object temperature, so it is suitable to mask the clouds at night.

\subsection{The Comparison with the Satellite Retrieval SST and Buoy SST}

In order to verify the accuracy and quality control of the retrieval SST with satellite data, the 49 group data are obtained through the retrieval SST matches the buoy data in same time and position in February 2016. The mean value and the variance are calculated with the difference of the retrieval SST and buoy SST. The mean value -3.85 shows the retrieval SST is the lower than the observational SST. The variance 3.89 suggests that the total error is the greater. The fitting equation of the observational SST and the retrieval SST is shown as follow:

$$
S S T_{o}=0.728 S S T_{s}+6.91
$$

The above fitting equation has estimated the overall trend of the observational SST and the retrieval SST.

\subsection{The Comparison with the Retrieval SST and Grid SST}

The correlation is calculated with 1750313 group SST which are obtained by terms of matching the retrieval SST and NCEP optimal SST, respectively, in the same position and time. The mean value and the variance are calculated with the difference of the retrieval SST and NCEP optimal SST. The mean value -0.627 shows the retrieval SST is the lower than the NCEP optimal SST. The variance 2.917 suggests that the total error is the greater. The fitting equation of the NCEP optimal SST and the inversion SST is shown as follow:

$$
S S T_{o i}=0.6079 S S T_{s}+9.43
$$

The equation shows that the retrieval SST with satellite data has the greater difference compared with the NCEP optimal SST, as means that the fine SST is necessary in the Huang-Bohai sea.

\subsection{The Comparison with the Buoy SST and Grid SST}

In order to make the fitting of the buoy SST and NCEP optimal SST, the 42821 group SST are obtained in the same position and time. The mean value and the variance are calculated with the difference of the buoy SST and NCEP 
optimal SST. The mean value 0.07 shows buoy SST is the lower than the NCEP optimal SST. The variance 1.82 suggests the total error is the lower. The fitting equation of NCEP optimal SST and the inversion SST is shown as follow:

$$
S S T_{o i}=0.912 S S T_{o}+1.83
$$

Above formula presents a good fitting of the NCEP optimal SST and the buoy SST.

\subsection{The Discussion of Quality Controlling Problem}

The retrieval SST with satellite data has the difference of $3^{\circ} \mathrm{C} \sim 4^{\circ} \mathrm{C}$ between buoy SST and the optimal interpolation SST according to the statistical analysis results of the retrieval SST with satellite data, NCEP optimal interpolation SST and buoy SST. Moreover, the linear correlation is higher between the buoy SST and the optimal interpolation SST, but the mean value and variance between them are the less than the mean and variance between above two type data and the retrieval SST. Therefore, the formula (3) as a reference value is utilized to control the quality of the retrieval SST.

The statistical equation can use as a quality control equation of merging the retrieval SST. The control processes firstly transfer the retrieval SST into the fitting SST, and the fitting SST is called as the statistics optimal interpolation SST in the next context. And then the difference of the statistics optimal interpolation SST and the retrieval SST is calculated. Meanwhile the variance 2.917 of the difference of the retrieval SST and the statistics optimal interpolation SST refers as quality control value. In the fusion, the quality control value is appropriately expanded to $3.0^{\circ} \mathrm{C}$. Finally, the SST is retained when the difference of the statistics optimal interpolation SST and the retrieval is less than $3.0^{\circ} \mathrm{C}$, and the SST is removed when the difference is greater than $3.0^{\circ} \mathrm{C}$.

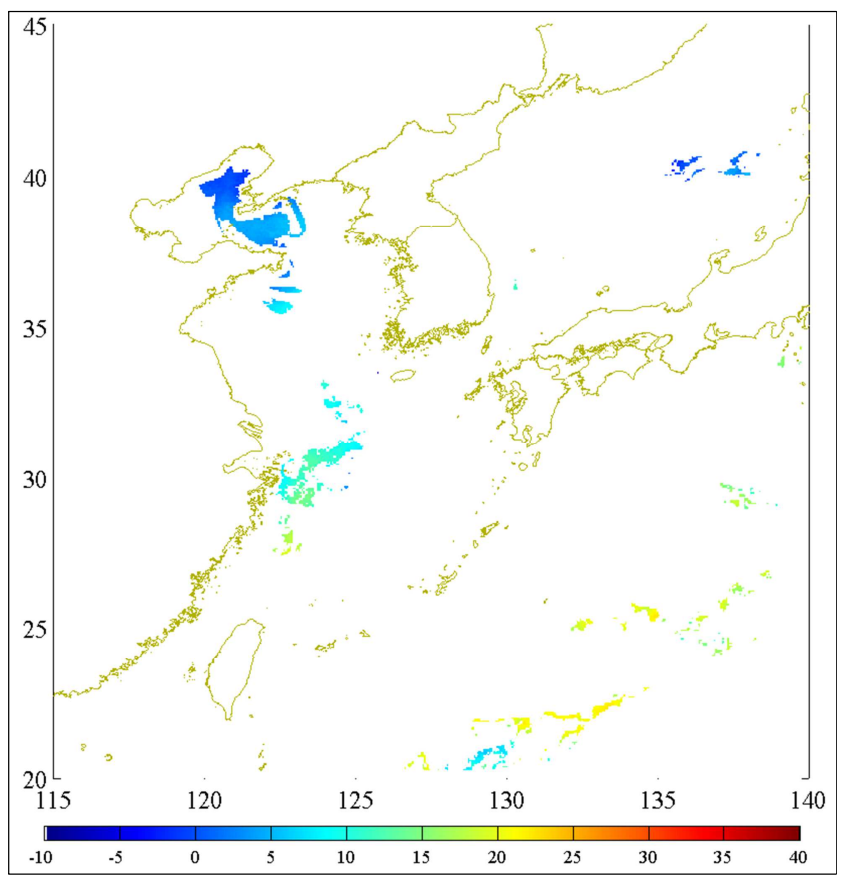

(a) the inversion SST with geostationary satellite data in fine sky area

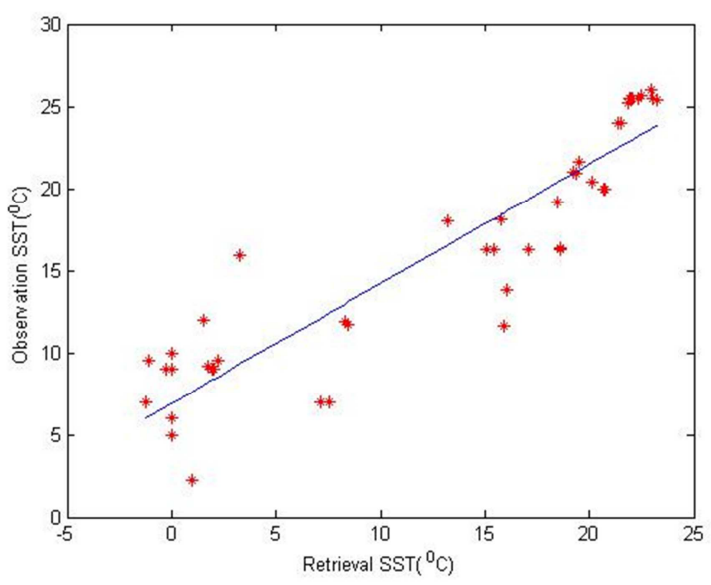

(b) the scatter of the inversion SST and buoy SST

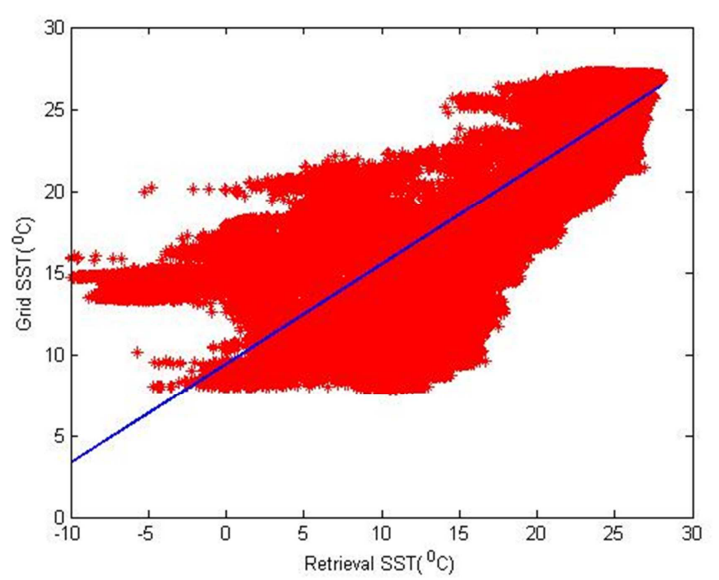

(c) the scatter of the geostationary satellite data and optimal SST

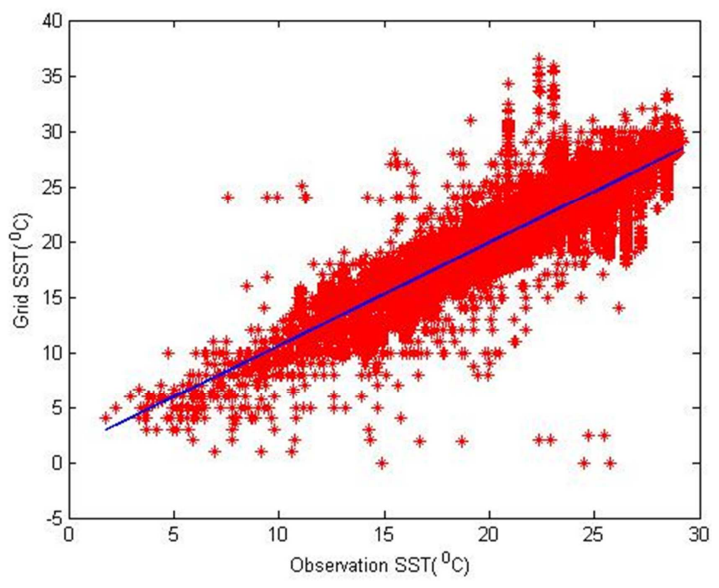

(d) the scatter of the optimal SST and buoy SST

Fig. 3. The statistics analysis of the inversion SST and the compared SST.

\section{The Fusion Analysis of the Retrieval SST with Geostationary Satellite Data}

\subsection{The Necessity and Method of the SST Fusion}

The retrieval SST with satellite data is significantly lower than the NCEP weekly average SST when the actual SST is below $10^{\circ} \mathrm{C}$. Due to the $1^{\circ} \times 1^{\circ} \mathrm{NCEP}$ weekly average SST doesn't 
contain the information of the weekly change and the spatial variation in Bohai Bay, it is necessary to improve NCEP weekly average SST with the retrieval SST. The improvement way is the utility of formula (5) and (6), which merge the high temporal and spatial resolution information into the NCEP weekly average SST. The region of the retrieval SST in composite must be more than 50 pixels in order to avoid excessively adjusting the local SST value when the difference of the retrieval SST and the optimal interpolation SST is the bigger.

\subsection{The Discussion of the SST Fusion Results}

The first guess field of the retrieval SST is adopted with the NCEP optimal interpolation weekly average SST which could represent the SST climatic features in Huang-Bohaisea. In data fusion process, the region with more satellite coverage is selected in Bohai Bay. In addition, the masking data of the land-sea is same as the one of satellite retrieval data.

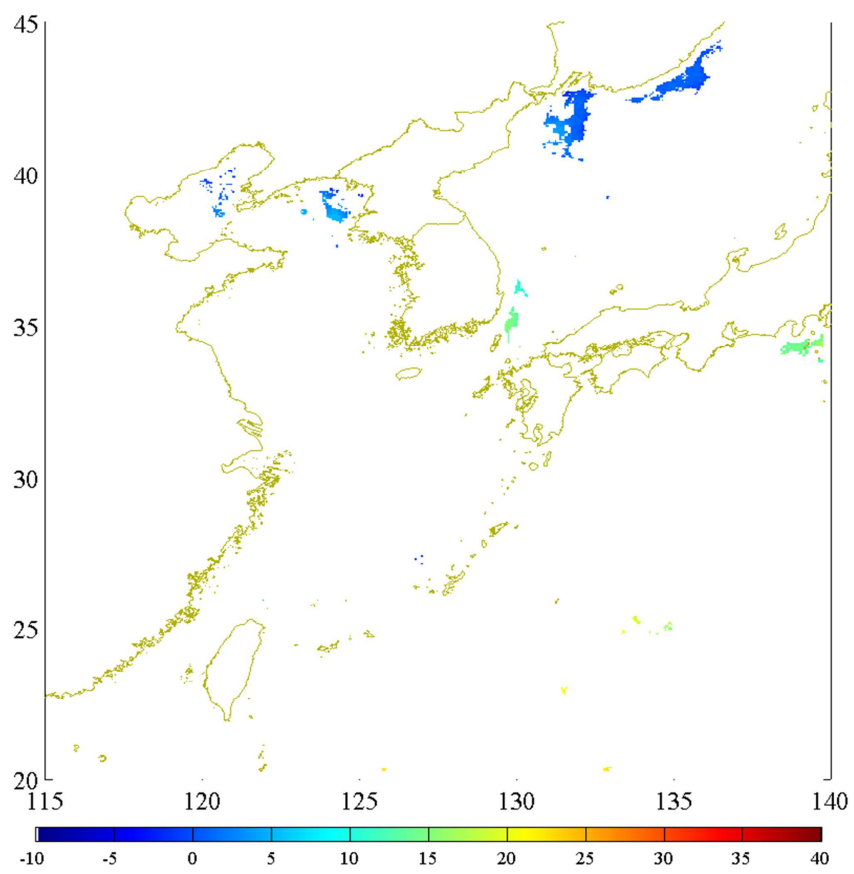

(a) morning

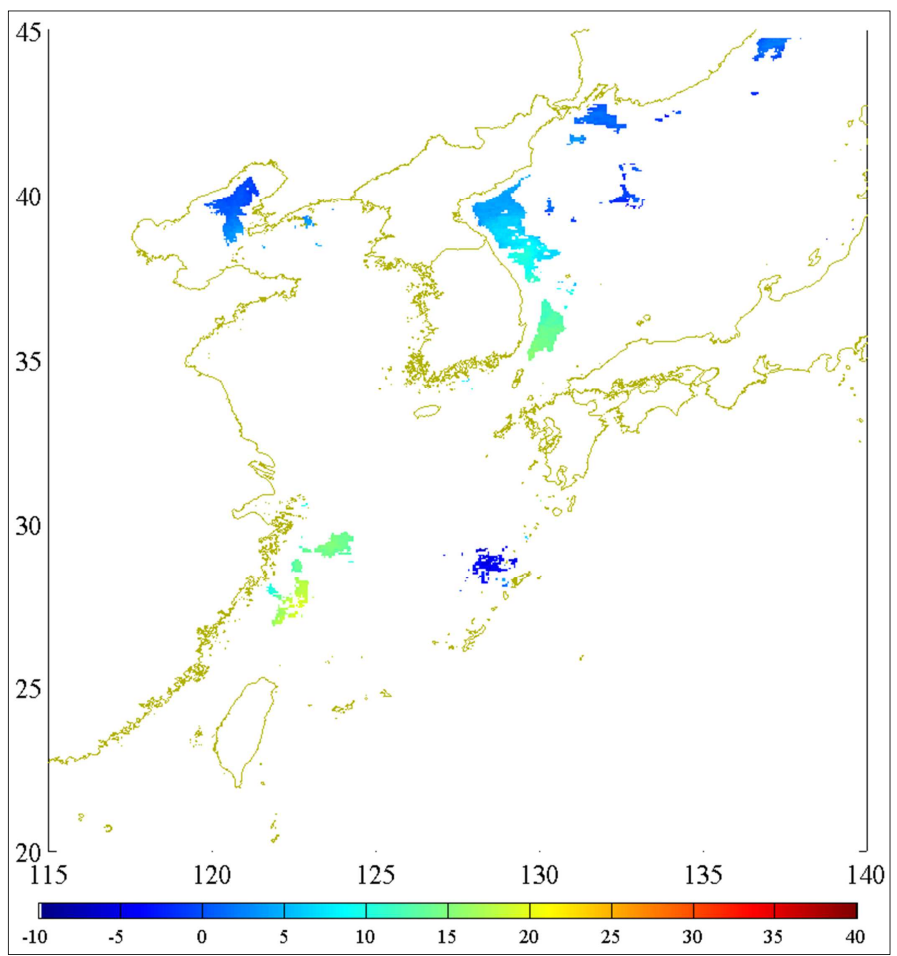

(b) noon 


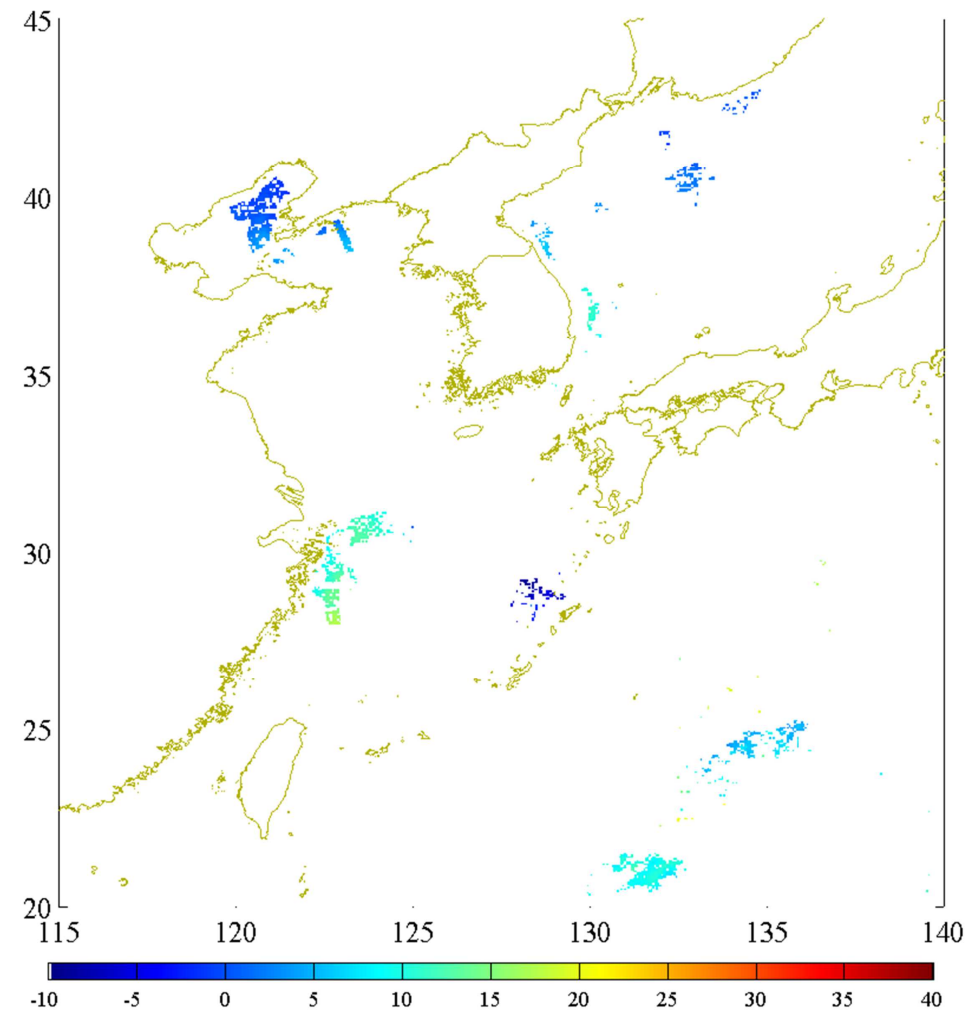

(c) night

Fig. 4. The satellite retrieval SST chart on $15^{\text {th }}$ February 2016.

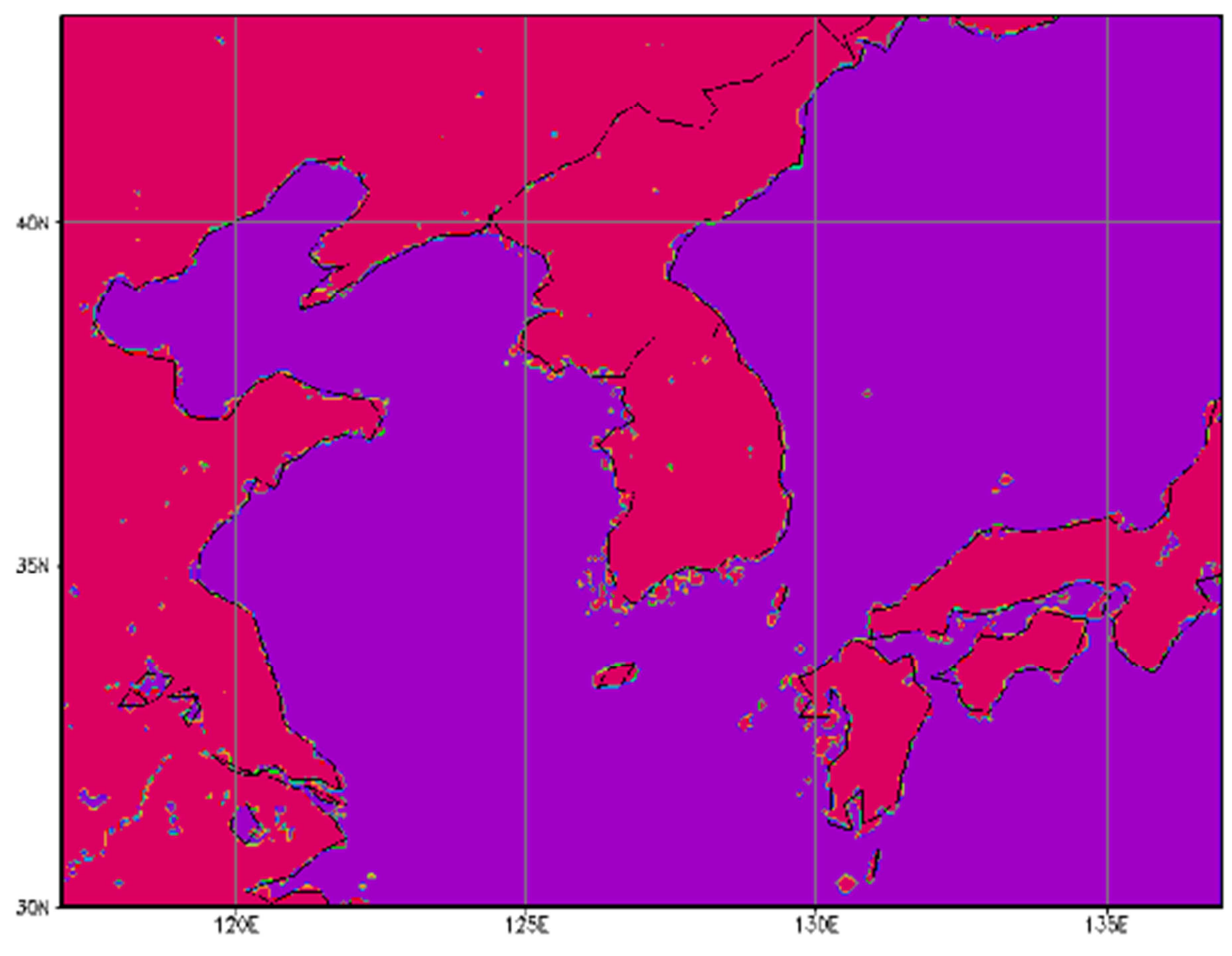

(a) the mask chart of the sea-land 


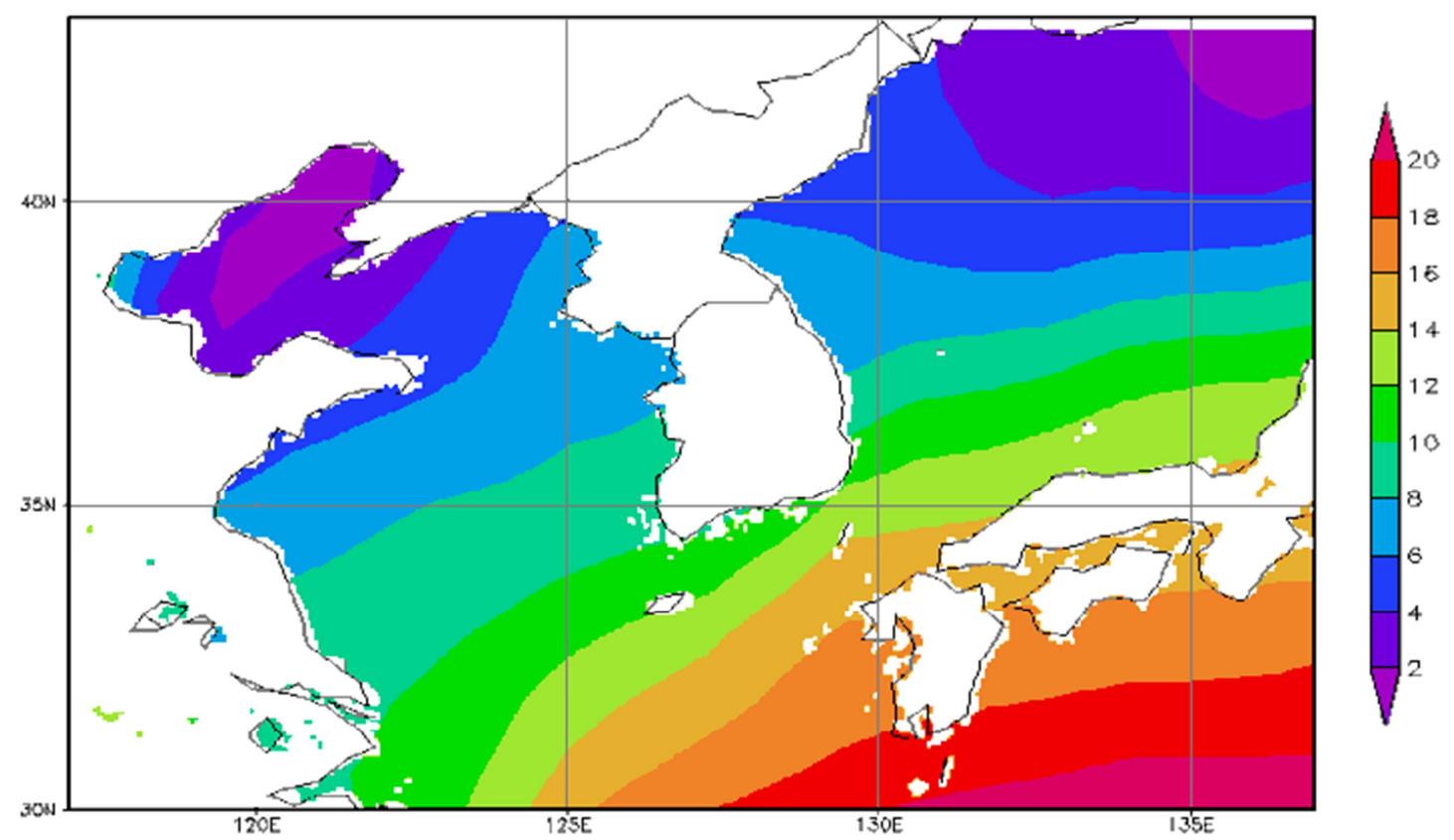

(b) the optimal interpolation SST

Fig. 5. The mask chart of the sea-land and the chart of the optimal interpolation SST in the second week February 2016.

The merged SST significantly increases the temporal and spatial information in Huang-Bohai sea for the application of the numerical weather prediction model. The satellite merged data is divided into 2 kinds of situation, namely the daily and half daily merged data. The more spatial characteristics of the retrieval information could be integrated into the NCEP grid data in Bohai Bay when the little cloud coverage exists. The daily fusion SST firstly makes some hourly retrieval SST into a composite, and then uses formula (3) as quality control equation. Finally, the retrieval SST is integrated into the weekly average optimal interpolation SST with the formula (5) and (6) after the data quality controlling. The half daily fusion is divided into daytime and nighttime data, and the daytime and nighttime data are integrated into a composite respectively. Finally, the semi-daytime fusion SST is calculated.

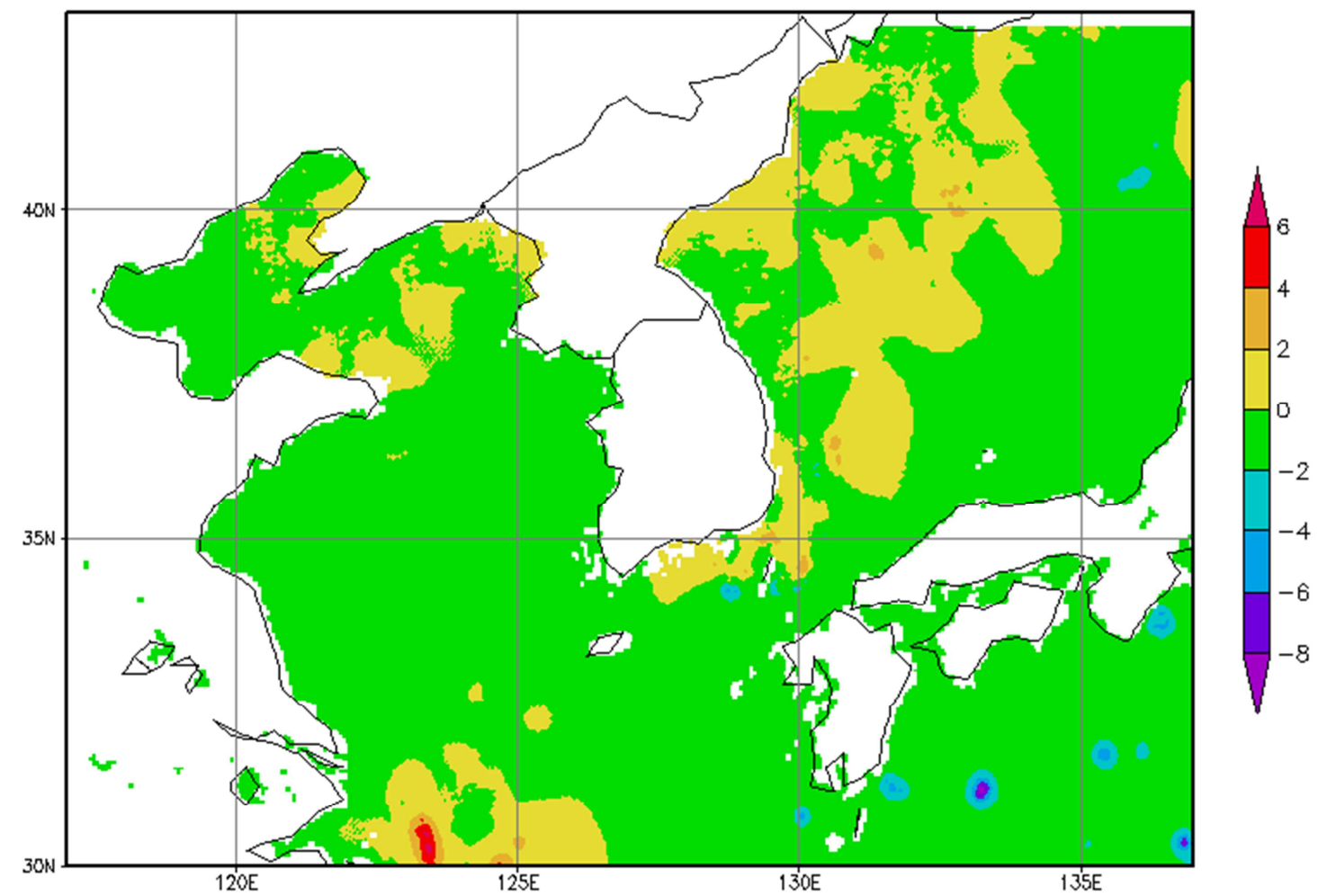

(a) daily fusion deviation 


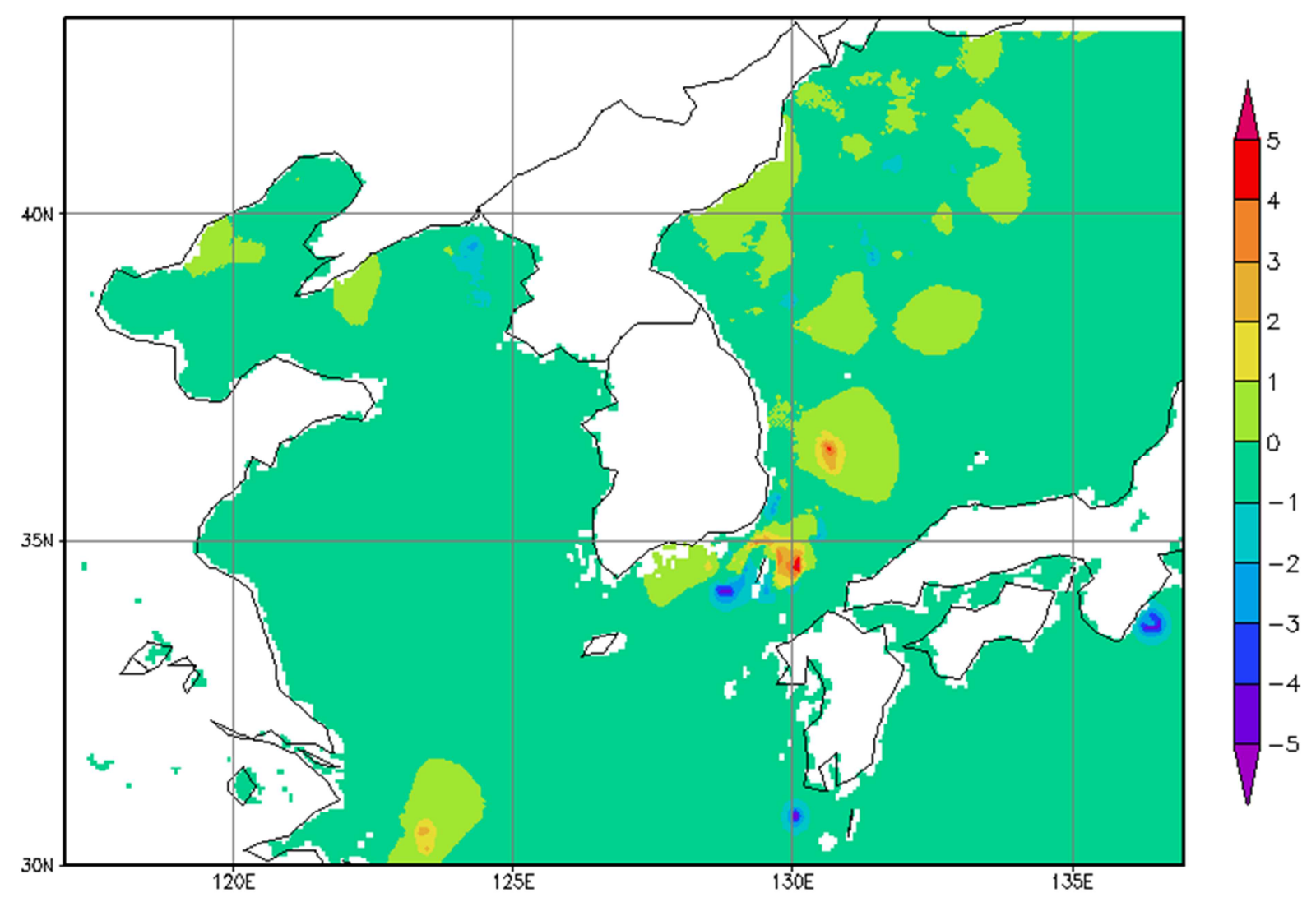

(b) day fusion deviation
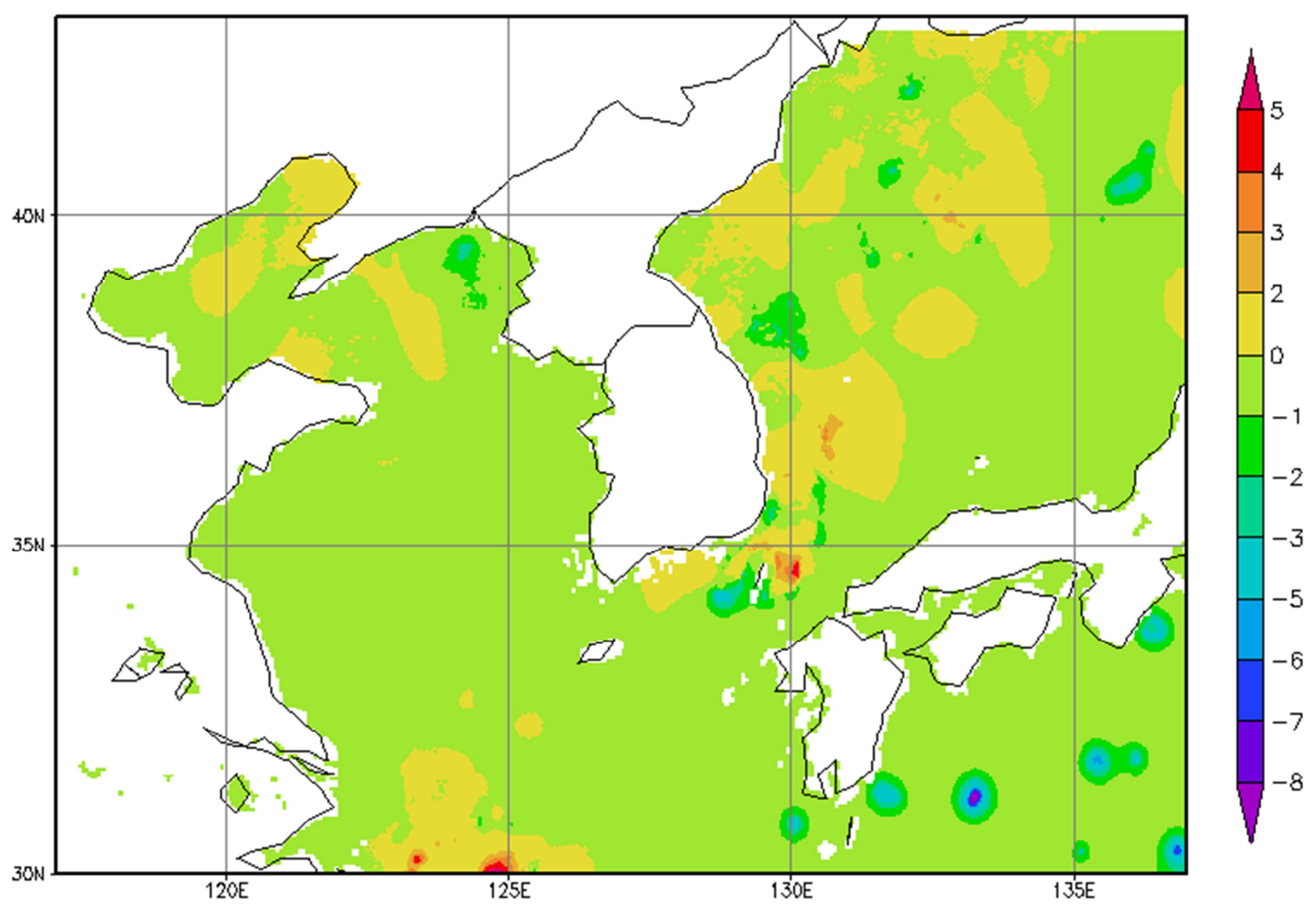

(c) night fusion deviation 


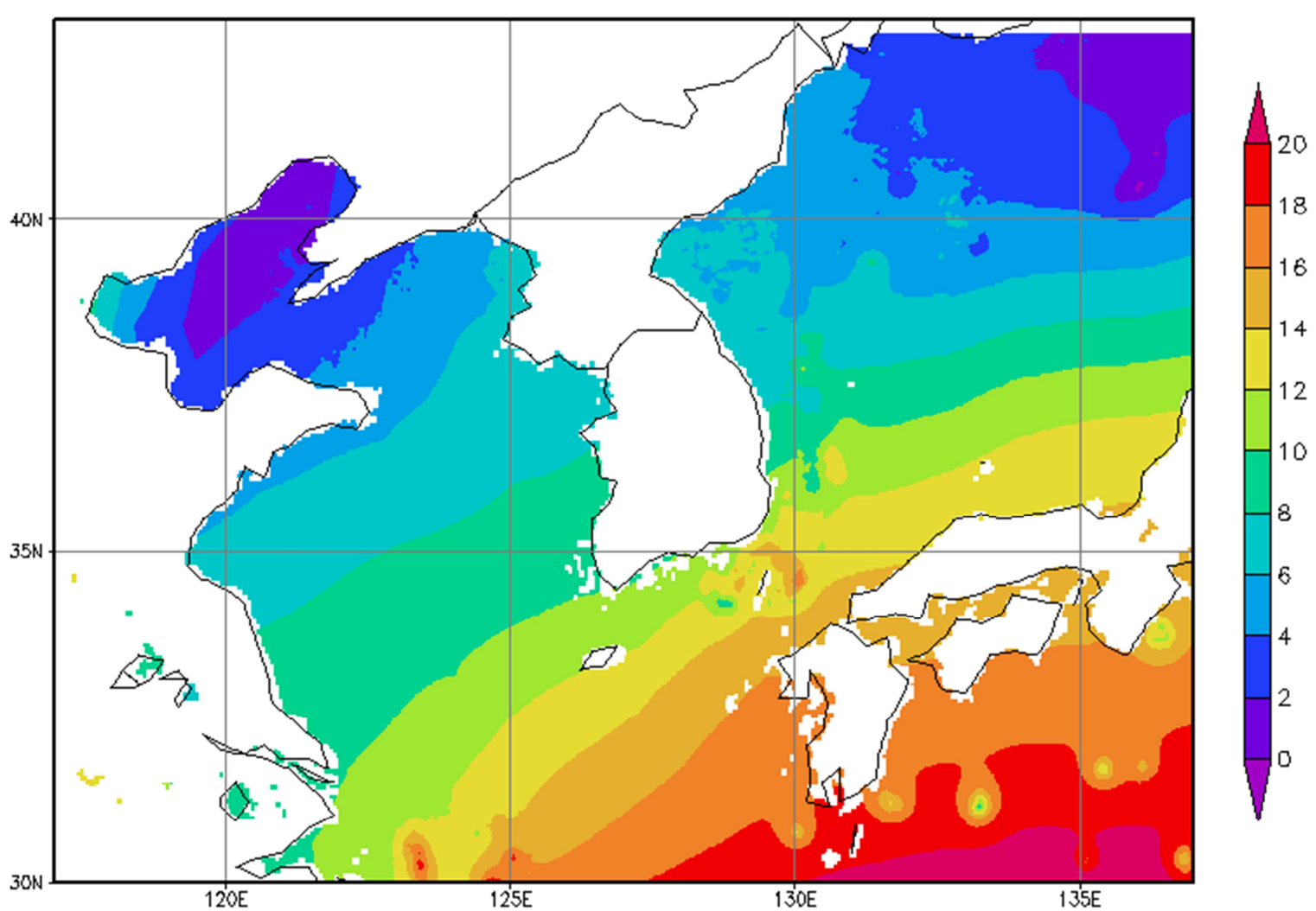

(d) daily fused SST

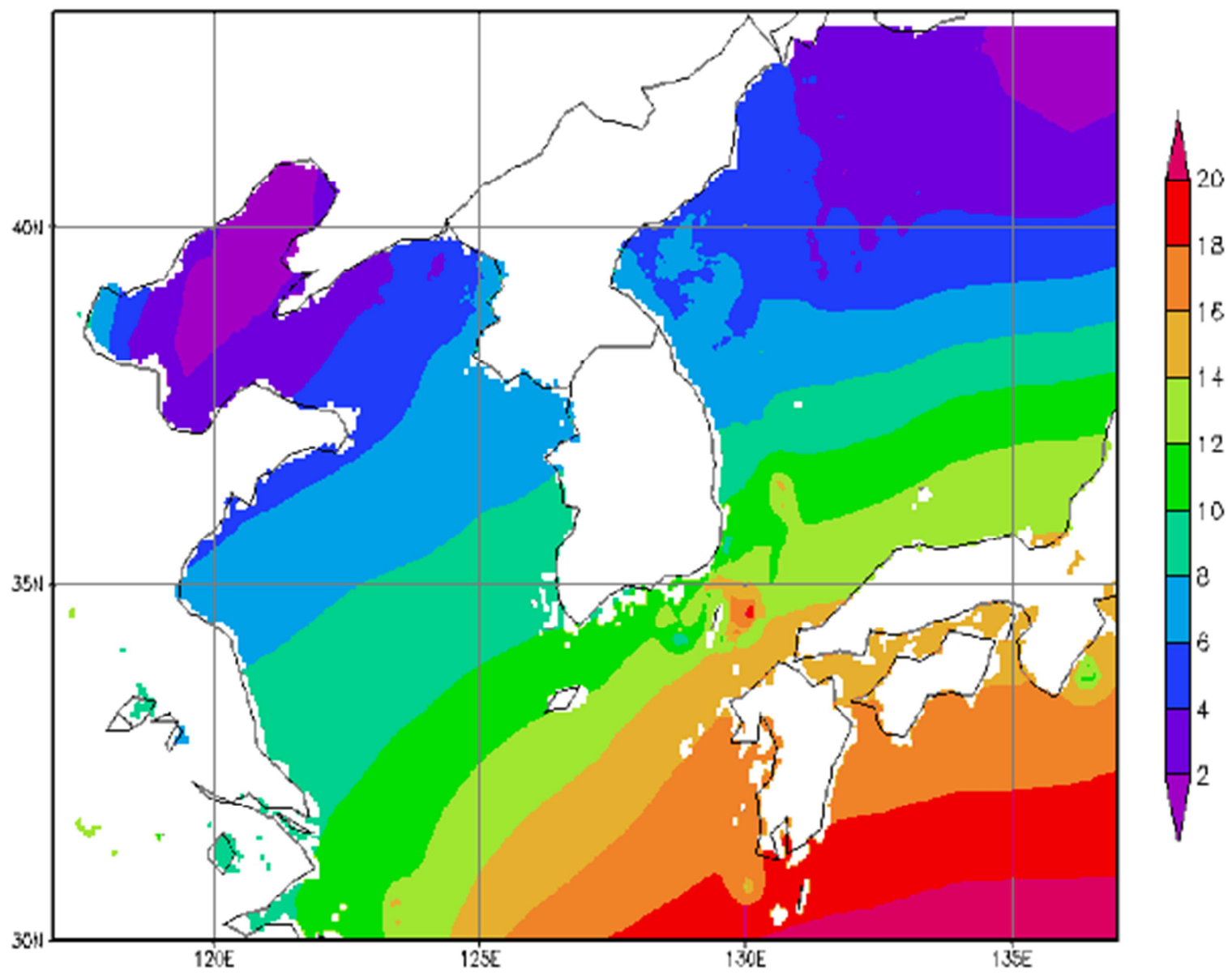

(e) day fused SST 


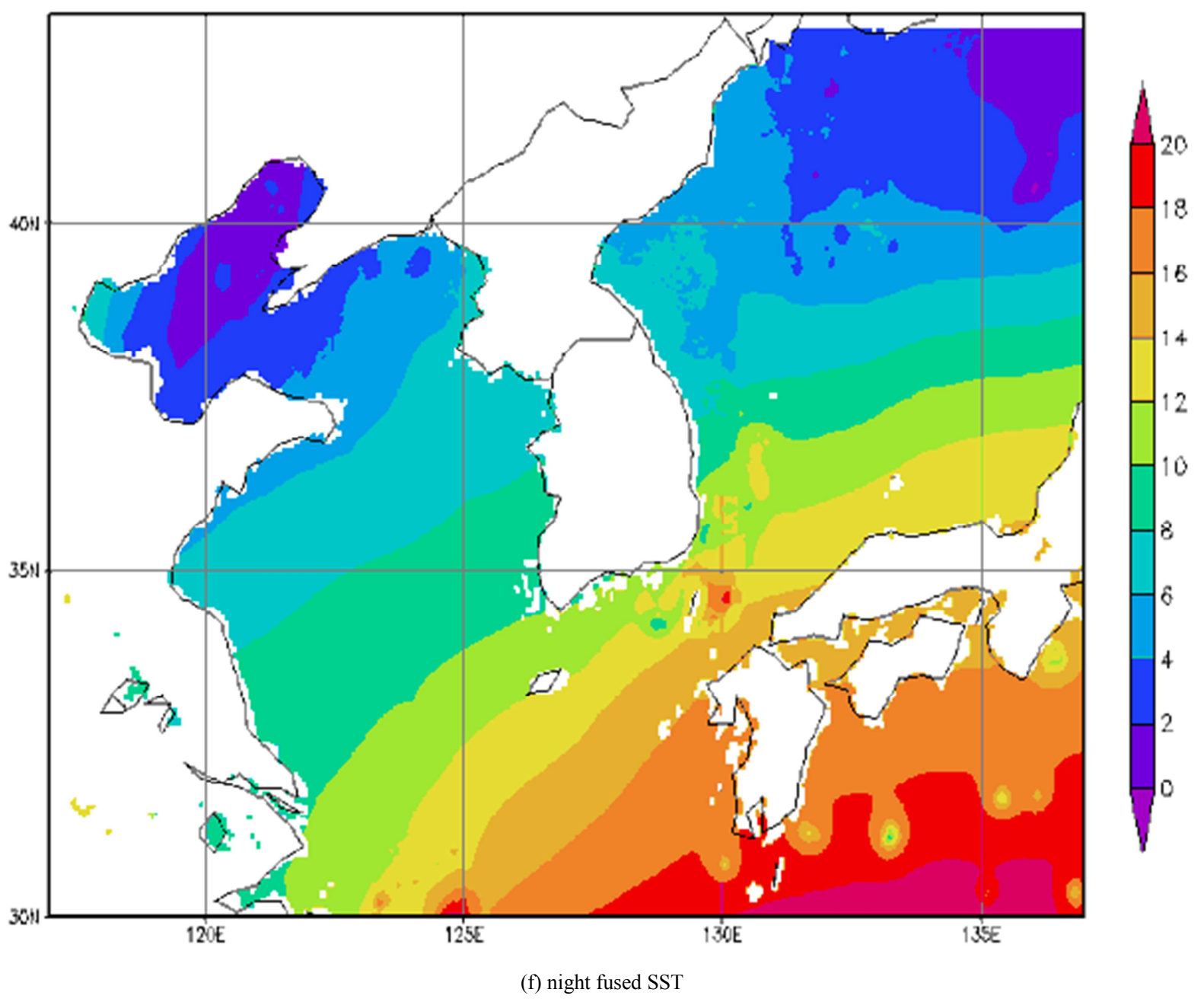

Fig. 6. The fusion char of the satellite retrieval SST.

\subsection{The Reliability Analysis of the Merged SST}

The statistical analysis results show that the overall error is $1.82^{\circ} \mathrm{C}$ between the buoy SST and NCEP optimal interpolation SST. The merged SST error is less than $1.8^{\circ} \mathrm{C}$ comparing with optimal interpolation SST in the sky region, and $1.0^{\circ} \mathrm{C}$ in the region of lack of satellite retrieval SST. Some research results represent that the error sometimes achieve $6^{\circ} \mathrm{C}$ to $9^{\circ} \mathrm{C}$ above when there is larger retrieval error due to the impact of low clouds, fog and cloud border. However, observed SST data also show that $24 \mathrm{~h}$ changes are rarely beyond $6^{\circ} \mathrm{C}$ in extreme cases, so the difference of $6^{\circ} \mathrm{C}$ is usually taken as a threshold of plausible SST (Knievel et al. 2010).

The lower error in the paper indicate that the merged SST could satisfy the plausible precision, so there is considerable application value to the numerical weather prediction model (Tuleya and Kurihara, 1982).

\section{The Conclusion}

The fusion SST with the retrieval SST and NCEP optimal interpolation SST solves problem of lack of high spatial and temporal resolution SST in Huang-Bohaisea.

The mean value and variance of the difference of the retrieval SST and the buoy SST are -3.85 and 3.89 respectively, meanwhile the mean and variance of the difference of satellite retrieval SST and the optimal interpolation SST are -0.627 and 2.917 respectively. If the FY2G-based retrieval SST is directly introduced to the numerical weather prediction model, the SST initial field will be underestimated according to the analysis results of the buoy SST, the NCEP optimal interpolation SST and the satellite retrieval SST. However, the merged SST could improve the low precision problem of the retrieval SST with satellite data under the situation of the lower SST, and promote SST resolution in Huang Bohai Bay.

The work lay a foundation of the detailed SST in Huang-Bohai sea for the numerical weather prediction model. But it is necessary to further improve satellite retrieval SST algorithm and fusion algorithm in order to promote the precision of daily fusion SST and the semidiurnal fusion SST.

\section{Acknowledgement}

The paper is financed by the fund of the key operational special plan of China Meteorological Administrative (CMAHX20160303). 


\section{References}

[1] Booth, J. F., Thompson, L., Patoux, J., et al. Sensitivity of Midlatitude Storm Intensification to Perturbations in the Sea Surface Temperature near the Gulf Stream [J]. MONTHLY WEATHER REVIEW, 2012, 140: 1241-1256.

[2] Emanuel, K. A. An air-sea interaction theory for tropical cyclones PartI: Steady-state maintenance [J]. Atmos. Sci., 1986, 43: 585-604.

[3] Fisher, J. I., Mustard, J. F. High spatial resolution sea surface climatology from Landsat thermal infrared data [J]. Remote Sensing of Environment, 2004, 90: 293-307.

[4] Knievel, J. C., Rife, D. L., Grim, J. A., et al. A Simple Technique for Creating Regional Composites of Sea Surface Temperature from MODIS for Use in Operational Mesoscale NWP [J]. JOURNAL OF APPLIED METEOROLOGY AND CLIMATOLOGY, 2010, 49: 2267-2284.

[5] MaulG, A.. Application of GOES visible-infraed data to quantifying mesoscale ocean surface temperature $[\mathrm{J}]$. Geophys. Res., 1981, 86: 8007-8021.

[6] Riehl, H. A model for hurricane formation [J]. Journal of Applied physics, 1950, 21: 917-925.

[7] Su J., Li L., Bao, X. W., et al. Numerical Experiment of SST

Response to Typhoon Process in Yellow Sea and Bohai Sea [J]. JOURNAL OF OCEAN UNIVERSITY OF QINGDAO, 2001, 31 (2): 165-172.

[8] Tuleya, R. E., Kurihara, Y. A note on the sea surface temperature sensitivity of a numerical model of tropical storm genesis [J]. Mon Weather Rev, 1982, 110: 2063-2069.

[9] Wang, J. H., Shao, C. X., Miao, C. S., et al. Near-shore SST's impact on typhoon return to the sea in numerical simulation [J]. JOURNAL OF TROPICAL OCEANOGRAPHY, 2012, 31 (5): 106-115.

[10] Wang, L., Zhang, R. H., Zhang, H. L. Analyses of Spatial-Temporal Characteristics For Various Seasonal Sea Surface Temperature Versus Summer Rainfall In China [J]. JOURNAL OF TROPICAL METEOROLOGY, 2007, 23 (6): 587-594.

[11] Wentz, F. J., Gentemann, C. D., Smith, D., et al. Satellite Measurements of Sea Surface Temperature Through Clouds [J]. Science, 2000, 288: 847-850.

[12] Yu, B., BoerG, J., Zwiers, F. W. Surface heat flux feedback and SST variability [J]. Trans. Atmos. Sci., 2011, 34 (1): 1-7.

[13] Yu, J. J., He, J. H., Shen, X. Y.. A Dynamical Study about the Impacts of SST and SSTA on Low Frequency Oscillation in Tropical Atmosphere [J]. Journal of Nanjing Institute of Meteorology, 2006, 29 (5): 688-693. 